\title{
Treatment trends in patients with asthma-COPD overlap syndrome in a COPD cohort: findings from a real-world survey
}

This article was published in the following Dove Press journal:

International Journal of COPD

15 June 2017

Number of times this article has been viewed

\author{
Bo Ding' \\ Mark Small ${ }^{2}$ \\ 'AstraZeneca Gothenburg, Mölndal, \\ Sweden; ${ }^{2}$ Adelphi Real World, \\ Bollington, Macclesfield, UK
}

Background: Asthma and chronic obstructive pulmonary disease (COPD) overlap syndrome (ACOS) is an increasingly recognized phenotype. Few randomized clinical trials have been conducted in patients with ACOS; therefore, scientific evidence concerning ACOS is scarce and a therapeutic approach remains unclear. The aim of this study was to evaluate current treatment trends for patients with ACOS, identified as those with a dual definition of asthma and COPD, in a real-world COPD cohort.

Methods: Data were analyzed from patients with asthma and COPD in the USA, France, Germany, Italy, Spain, and the UK who participated in the 2012 and 2013 Adelphi Respiratory Disease Specific Programmes (DSPs). Patients with ACOS were identified in the COPD population; these patients had a physician-confirmed, concomitant asthma diagnosis. Physicians completed a patient record form providing information on patient and disease characteristics including prescribed respiratory treatment. Pairwise comparisons were made between the ACOS, asthma, and COPD populations using $\chi^{2}$ tests.

Results: In total, 9,042 patients with asthma-only, 7,119 patients with COPD-only, and 523 patients with ACOS (a dual diagnosis of asthma and COPD) participated in the study. The most commonly prescribed regimens were inhaled corticosteroid/long-acting $\beta_{2}$-agonist (ICS/LABA) + long-acting muscarinic antagonist (LAMA); (ACOS 30\%, asthma $1.4 \%$, and COPD $32 \%)$, ICS/LABA (19\%, 41.5\%, and 17\%, respectively), and LAMA (6\%, $0.4 \%$, and $19 \%$, respectively); $18 \%$ of patients with ACOS were not prescribed an ICS. Patients with ACOS had a significantly higher incidence of gastroesophageal reflux disease, diabetes, and obesity and experienced more exacerbations in the past year than those with COPD or asthma.

Conclusions: The majority of patients with ACOS, as defined in this research, were prescribed similar treatment to those with COPD. There is a need, however, for better treatment for patients with ACOS, as indicated by symptoms and exacerbation levels. A clearer therapeutic approach for patients with ACOS is required.

Keywords: asthma-COPD overlap syndrome, asthma, chronic obstructive pulmonary disease, ACO, pharmacotherapy

\section{Introduction}

Asthma and chronic obstructive pulmonary disease (COPD) are respiratory conditions characterized by bronchial obstruction presenting with chronic inflammation. Asthma is defined by a history of respiratory symptoms such as wheeze, shortness of breath, chest tightness, and cough that vary over time and in intensity, together with variable expiratory flow volume and reversibility. ${ }^{1}$ COPD is a common, preventable, and treatable disease that is characterized by persistent respiratory symptoms and airflow
Correspondence: Bo Ding AstraZeneca Gothenburg, Pepparedsleden I, SE-43I 83 Mölndal, Sweden

Tel +46 3I 7762406

Email bo.ding@astrazeneca.com 
limitation attributable to airway and/or alveolar abnormalities, usually caused by significant exposure to noxious particles or gases; COPD has little or no reversibility. ${ }^{2}$

A sizable proportion of patients presenting with airway obstruction have symptoms of both conditions, and the term asthma and COPD overlap syndrome (ACOS) has been coined to describe this population. ACOS was recently recognized by the Global Initiative for Asthma (GINA) and the Global Initiative for Chronic Obstructive Lung Disease (GOLD), who defined this condition as being characterized by persistent airflow limitation together with several features usually associated with asthma or COPD. ${ }^{3}$ The relatively recent recognition of this condition has resulted in different definitions of ACOS being used; consequently, estimates of the prevalence of ACOS have ranged from $12 \%$ to $55 \%$ of patients with chronic obstructive airway diseases. ${ }^{4}$

Patients with ACOS experience more severe symptoms than those with either asthma or COPD alone, with more frequent and more severe exacerbations ${ }^{5}$ and more frequent hospitalizations. ${ }^{4}$ Patients with ACOS have been shown to be significantly younger than those with COPD, with a higher body mass index (BMI), ${ }^{6}$ and greater medical resource utilization and economic burden. ${ }^{7,8}$

Despite this considerable prevalence of ACOS, few randomized controlled trials have been performed in patients with ACOS and a clear pharmacotherapeutic approach is yet to be established for ACOS. The present study was undertaken to assess treatment trends in patients with ACOS using data from the Adelphi Real World Respiratory Disease Specific Programmes (DSPs) conducted in the EU5 (Spain, Italy, France, Germany, and the UK) and the USA - countries with similarly advanced healthcare systems. Furthermore, we explored the clinical characteristics of patients with ACOS compared with an asthma-only and a COPD-only population in order to better understand these patients.

\section{Methods}

The Adelphi DSPs are large, cross-sectional surveys of physicians and patients in the real-world clinical setting, using representative sampling of treated patients for the assessment of treatment patterns and outcomes. ${ }^{9}$

Data for this analysis were drawn from the Respiratory DSPs conducted during 2012 and 2013 in the USA and EU5.

Physicians were identified by local fieldwork teams from public lists according to predefined selection criteria. Specifically, physicians were required to have been qualified for a minimum of 5 years and a maximum of 35 years, to be actively involved in the management of patients with asthma and COPD, and to see at least three patients with asthma and three patients with COPD per month.

The Respiratory DSPs collected information from patients diagnosed with asthma and COPD who were consulting a physician for routine care. Patients with asthma-only were required to be $\geq 12$ years of age, to have a physician-confirmed diagnosis of asthma, and no diagnosis of COPD. Patients with COPD-only were required to be $>40$ years, a key age threshold for patients with COPD, to have physician-confirmed airflow obstruction, a diagnosis of COPD, and no diagnosis of asthma. Airflow obstruction was confirmed by the physician based on available patient information, without a requirement for forced expiratory volume in 1 second $\left(\mathrm{FEV}_{1}\right)$ / forced vital capacity (FVC) testing, as use of the GOLD-recommended $\mathrm{FEV}_{1} / \mathrm{FVC}$ ratio of 0.7 can lead to an incorrect diagnosis of airflow obstruction in elderly patients. ${ }^{10}$ Patients with ACOS were identified in the COPD population and were required to have physician-confirmed airflow obstruction, a diagnosis of COPD (that could include emphysema and chronic bronchitis), and a physician-confirmed diagnosis of asthma, which could have occurred before, after, or simultaneously with their COPD diagnosis. Patients were required to have a diagnosis of both asthma and COPD on the day of the consultation in order to avoid the incorrect inclusion of a patient with a historical diagnosis of one condition and a current diagnosis of the other condition; such a patient would not have a dual diagnosis on the day of the consultation.

Treatments received by patients with ACOS were stratified according to whether the patient had pre-existing asthma before their COPD diagnosis, or whether they had been diagnosed with both conditions (ACOS) for the same duration.

Patients with ACOS were stratified according to whether the patient had asthma first and then was diagnosed with COPD, had COPD first and then was diagnosed with asthma, or both conditions were diagnosed simultaneously; treatment received was analyzed in these three groups.

The research was conducted as a market research survey in accordance with the amended Declaration of Helsinki, adhering to the ICC/ESOMAR International Code on observational research ${ }^{11}$ and performed in full accordance with the rules of the US Health Insurance Portability and Accountability Act $1996^{12}$ and the European Pharmaceutical Marketing Research Association guidelines. ${ }^{13}$ Consequently, ethics approval was not needed and was not sought. All data were de-identified before receipt by Adelphi Real World and were aggregated.

\section{Data collection}

Physicians were asked to complete physician report forms for the next five patients with asthma and the subsequent 
five patients with COPD. The former provided the group of patients with a diagnosis of asthma-only; patients in the COPD group who also had a diagnosis of asthma on the day of the consultation formed the ACOS group, whereas those who had no diagnosis of asthma formed the COPD-only group. The physician report form collected information on patient demographics, clinical characteristics, clinical management, and outcomes (including exacerbation history in the last 12 months and physician perception of exacerbation risk [high or low]; exacerbations were defined as a worsening of symptoms beyond normal day-to-day variations), and medication use and history.

The same patients were then invited to provide details relating to their condition via a patient self-completion form. These were filled out separately and confidentially, with no influence or input from the physician or nurse. Completion of this form was not mandatory.

\section{Study objectives}

The primary aim of this research was to compare the current treatment prescribed for patients with ACOS versus those for patients with asthma-only or COPD-only. Secondary objectives were to assess whether treatment trends for patients with ACOS were associated with clinical characteristics of patients and/or physician type, and to compare ACOS treatments for patients with pre-existing asthma versus patients diagnosed with ACOS. Exploratory objectives of this research were to further characterize patients with ACOS and compare them against patients with COPD-only and those with asthma-only.

\section{Statistical analyses}

Data from the 2012 and 2013 DSPs were pooled to increase sample sizes. All analyses were conducted using Stata version 13.1 or later (StataCorp. 2013. Stata Statistical Software: Release 13. College Station, TX: StataCorp LP). Descriptive statistics were generated for the study population, with mean values and medians as appropriate.

Statistical differences across various subpopulations were assessed, dependent on the distribution and type of the variable being analyzed. All statistical tests performed were two sided and used a 5\% significance level. Bonferroni adjusted $P$-values were calculated for pairwise comparisons where necessary.

For categorical data, Pearson's $\chi^{2}$ tests were performed to test for significant differences between subgroups; Kruskal-Wallis tests were performed for continuous data not considered to be normally distributed or ordinal.
Differences in patient demographics, treatment class prescribed, and symptomatology were analyzed across three patient groups (asthma-only, COPD-only, and ACOS).

Further stratification of the ACOS population by the three main treatments received by patients was:

- long-acting muscarinic antagonist (LAMA) monotherapy

- inhaled corticosteroid (ICS)/ long-acting $\beta_{2}$-agonist (LABA)

- ICS/LABA + LAMA.

Differences between treatment and clinical characteristics of the patient and the type of physician currently responsible for treatment decisions were identified.

\section{Results}

A total of 9,048 patients with asthma-only (ie, currently aged $\geq 12$ years), 7,146 patients with COPD-only, and 527 patients with ACOS were included in the survey; of these, 9,042 patients with asthma-only, 7,119 patients with COPD-only, and 523 patients with ACOS comprised the eligible study population.

Patient demographics and clinical characteristics are shown in Table 1. Notable between-group differences were observed in sex (53\% of patients with ACOS were male compared with $66 \%$ of those with COPD and $45 \%$ of those with asthma), age (median age was 40 years in the asthma group compared with 66 years in both the ACOS and COPD groups), BMI (mean BMI was significantly lower in patients with asthma compared with COPD and ACOS), and smoking status $(70 \%$ of patients with asthma had never smoked, as compared with $3 \%$ of patients with COPD and $5.5 \%$ of those with ACOS). Compared with patients with asthma-only, patients with ACOS had a higher prevalence of comorbidities including hypertension, elevated cholesterol/hyperlipidemia, arthritis, depression, obesity, and gastroesophageal disease. The prevalence of gastroesophageal reflux disease (GERD), depression, diabetes, osteoporosis, and obesity was higher in patients with ACOS as compared with those with COPD-only (Table 1). Regardless of the complexity of their condition, a similar proportion of patients with ACOS, asthma, and COPD were treated by primary care physicians.

Characteristics of patients in the US and EU5 populations are shown in Table $\mathrm{S} 1$.

\section{Prescribed treatment}

Patients were generally treated by a pulmonologist (42\%, $57 \%$, and $51 \%$ of patients with asthma-only, COPD-only, and ACOS, respectively) or a primary care physician only (39\%, 39\%, and 42\%, respectively) as shown in Table 1 . 
Table I Patient characteristics

\begin{tabular}{|c|c|c|c|c|}
\hline Characteristic & $\begin{array}{l}\text { Adult asthma-only } \\
(\mathrm{n}=9,042)\end{array}$ & $\begin{array}{l}\text { COPD-only } \\
(n=7,119)\end{array}$ & $\begin{array}{l}\text { ACOS } \\
(n=523)\end{array}$ & $P$-value ${ }^{a}$ \\
\hline Age, years & & & & $<0.001(\mathrm{KW})$ \\
\hline Median & 40.0 & 66.0 & 66.0 & \\
\hline Mean (SD) & $42.0(16.9)$ & $65.9(10.5)$ & $65.2(10.7)$ & \\
\hline Age group, \% & & & & $<0.000 \mathrm{I}(\mathrm{KW})$ \\
\hline$<40$ years & 47.4 & 0 & 0 & \\
\hline 40-49 years & 20.3 & 7.1 & 9.3 & \\
\hline 50-59 years & 14.8 & 20.2 & 19.0 & \\
\hline $60-69$ years & 10.3 & 33.8 & 35.2 & \\
\hline 70-79 years & 5.3 & 28.0 & 28.0 & \\
\hline$\geq 80$ years & 1.8 & 10.9 & 8.5 & \\
\hline Missing & $<1$ & $<1$ & $<1$ & \\
\hline Sex, \% & & & & $<0.00 \mathrm{I}(\mathrm{PC})$ \\
\hline Male & 44.6 & 66.0 & 52.7 & \\
\hline Female & 55.4 & 34.0 & 47.3 & \\
\hline Mean BMI, kg/m² & 26.0 & 26.7 & 27.6 & $<0.00 \mathrm{I}(\mathrm{KW})$ \\
\hline Range & $9.0-83.3$ & $7.5-60.3$ & $16.5-55.9$ & \\
\hline Smoking status, \% & & & & $<0.001(\mathrm{PC})$ \\
\hline Current smoker & 10.5 & 32.0 & 31.8 & \\
\hline Ex-smoker & 19.4 & 65.3 & 62.7 & \\
\hline Never smoker & 70.2 & 2.7 & 5.5 & \\
\hline Mean pack-years, \% & 13.2 & 37.5 & 32.7 & $<0.00 \mathrm{I}(\mathrm{PC})$ \\
\hline \multicolumn{5}{|l|}{ Comorbidities, \% } \\
\hline Elevated cholesterol/hyperlipidemia & 10.5 & 28.7 & 29.2 & $<0.001(\mathrm{PC})$ \\
\hline Hypertension & 19.9 & 58.8 & 56.2 & $<0.00 \mathrm{I}(\mathrm{PC})$ \\
\hline Anxiety & 10.4 & 12.2 & 18.3 & $<0.00 \mathrm{I}(\mathrm{PC})$ \\
\hline Arthritis & 4.5 & 12.5 & 16.6 & $<0.00 \mathrm{I}(\mathrm{PC})$ \\
\hline Depression & 8.0 & 12.3 & 21.3 & $<0.00 \mathrm{I}(\mathrm{PC})$ \\
\hline Diabetes & 6.0 & 17.8 & 21.9 & $<0.001(\mathrm{PC})$ \\
\hline GERD & 10.5 & 13.3 & 19.1 & $<0.00 \mathrm{I}(\mathrm{PC})$ \\
\hline Obesity & 8.5 & 9.4 & 13.0 & $0.0014(P C)$ \\
\hline Osteoporosis & 2.6 & 7.1 & 11.0 & $<0.001(\mathrm{PC})$ \\
\hline Treatment decisions, \% & & & & $<0.00 \mathrm{I}(\mathrm{PC})$ \\
\hline PCP-only & 39.1 & 38.5 & 41.7 & \\
\hline Allergist & 12.8 & 0.1 & 0.2 & \\
\hline Pulmonologist & 42.2 & 56.6 & 50.9 & \\
\hline Both allergist and pulmonologist & 1.8 & 0.1 & 1.1 & \\
\hline Other HCP & 4.1 & 4.7 & 6.1 & \\
\hline Mean no of exacerbations in the last 12 months $^{c}$ & 0.9 & 1.7 & 2.3 & $<0.00 \mathrm{I}(\mathrm{KW})$ \\
\hline Number of exacerbations in the last 12 months $^{c}$ & & & & $<0.000 \mathrm{I}(\mathrm{KW})$ \\
\hline 0 & 65.6 & 46.7 & 35.8 & \\
\hline $1-2$ & 21.1 & 28.0 & 29.4 & \\
\hline $3-4$ & 8.7 & 14.8 & 20.3 & \\
\hline $5+$ & 4.6 & 10.5 & 14.5 & \\
\hline \multicolumn{5}{|l|}{ Mean $\mathrm{FEV}_{1}, \%$ predicted } \\
\hline Pre-bronchodilator & 76.7 & 57.5 & 58.6 & $<0.00 \mathrm{I}(\mathrm{KW})$ \\
\hline Post-bronchodilator & 83.5 & 61.8 & 64.2 & $<0.00 \mathrm{I}(\mathrm{KW})$ \\
\hline \multicolumn{5}{|l|}{ Symptoms in last 4 weeks, $\%^{\mathrm{d}}$} \\
\hline Shortness of breath during exertion/exercise & 44.9 & 71.5 & 73.9 & $<0.001(\mathrm{PC})$ \\
\hline Wheezing & 30.4 & 29.7 & 42.0 & $<0.00 \mathrm{I}(\mathrm{PC})$ \\
\hline Productive cough/sputum & 16.5 & 50.8 & 54.8 & $<0.001(\mathrm{PC})$ \\
\hline Dry cough & 42.3 & 47.5 & 51.1 & $<0.00 \mathrm{I}(\mathrm{PC})$ \\
\hline Tight feeling in chest & 24.2 & 26.5 & 36.0 & $<0.00 \mathrm{I}(\mathrm{PC})$ \\
\hline
\end{tabular}

Notes: a Difference between all three treatment groups. ${ }^{\mathrm{b} C}$ Comorbidities occurring in $>10 \%$ of patients. 'Exacerbations were defined as: a worsening of symptoms beyond normal day-to-day variation requiring oral corticosteroids, antibiotics, or both, emergency room treatment, or hospitalization. By definition, these are moderate to severe

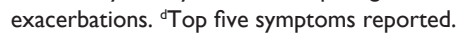

Abbreviations: ACOS, asthma and COPD overlap syndrome; BMI, body mass index; COPD, chronic obstructive pulmonary disease; GERD, gastroesophageal reflux disease; $\mathrm{HCP}$, health care provider; KW, Kruskal-Wallis test; PC, pairwise combination $\chi^{2}$ test; PCP, primary care physician; SD, standard deviation. 
The most commonly prescribed regimens across all diagnoses were ICS/LABA + LAMA (asthma 1.4\%, COPD 32\%, ACOS 30\%), ICS/LABA (asthma 41.5\%, COPD 17\%, ACOS 19\%), and LAMA monotherapy (asthma 0.4\%, COPD 19\%, ACOS 6\%). A full breakdown of prescribed treatment regimens for the three groups of patients is shown in Table 2; treatment according to geographic region is summarized in Table S1. The most commonly prescribed regimens in patients with asthma-only were ICS/LABA alone, ICS/LABA + leukotriene receptor antagonist, and ICS alone. Prescribing patterns were similar in patients with COPD-only and ACOS: the most commonly prescribed regimens were ICS/LABA + LAMA, LAMA alone, and ICS/LABA alone. Significant differences were observed between the asthma-only and ACOS populations in treatments prescribed; ACOS treatment more closely resembled that of the COPD-only population. Among patients with ACOS, leukotriene receptor antagonists were reported as the most common additional maintenance medication prescribed specifically for the asthma component of ACOS; $18.2 \%$ did not receive ICS-containing therapy.

\section{Relationship between ACOS treatment and clinical characteristics of patients or physician type}

Differences were observed in the clinical characteristics of ACOS patients receiving the three main treatment regimens

Table 2 Treatments most commonly associated with asthma, COPD, and ACOS

\begin{tabular}{llll}
\hline $\begin{array}{l}\text { Treatment, } \\
\text { \% of patients }\end{array}$ & $\begin{array}{l}\text { Asthma-only } \\
(\mathbf{n = 9 , 0 4 2 )}\end{array}$ & $\begin{array}{l}\text { COPD-only } \\
(\mathbf{n = 7 , 1 ~ I 9 )}\end{array}$ & $\begin{array}{l}\text { ACOS } \\
(\mathbf{n}=\mathbf{5 2 3})\end{array}$ \\
\hline SABA monotherapy & $10.9^{* * *}$ & $3.5^{*}$ & $1.5^{\mathrm{a}}$ \\
Short-acting therapy & 0.3 & 1.3 & $0.4^{\mathrm{a}}$ \\
ICS monotherapy & $15.5^{* * *}$ & $2.8^{* *}$ & 4.2 \\
LABA monotherapy & $1.2^{*}$ & 5.5 & $2.5^{\mathrm{a}}$ \\
LAMA monotherapy & $0.4^{* * *}$ & $19.4^{* * *}$ & $6.2^{\mathrm{a}}$ \\
ICS/LABA & $41.5^{* * *}$ & 16.7 & 19.2 \\
ICS + LABA & 2.3 & 1.3 & 1.5 \\
ICS + LAMA & $0.1^{* * *}$ & $1.4^{*}$ & 2.9 \\
LABA + LAMA & $0.02^{* * *}$ & $7.0^{* * *}$ & $2.5^{\mathrm{a}}$ \\
ICS/LABA + LABA & $0.5^{* * *}$ & $0.7^{* *}$ & 2.1 \\
ICS/LABA + LTRA & $11.6^{* * *}$ & $0.4^{* * *}$ & 4.4 \\
ICS/LABA + LAMA & $1.4^{* * *}$ & 32.0 & 29.6 \\
ICS + LABA + LAMA & $0.1^{* * *}$ & 2.1 & 3.3 \\
Other & 14.5 & 5.9 & $19.7^{\mathrm{a}}$ \\
\hline
\end{tabular}

Notes: $* P<0.05$ vs ACOS. $* * p<0.01$ vs ACOS. $* * * p<0.0001$ vs ACOS. Data were missing for 147 patients (2\%) with asthma-only, 58 patients (I\%) with COPD-only,

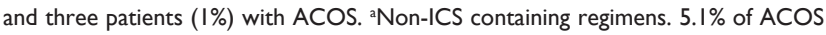
patients in the "Other" category received a non-ICS containing regimen. "'Other" category included less commonly prescribed combinations of the maintenance treatments listed. All combinations were \pm xanthines, biologic agents, oral corticosteroids, and antibiotics.

Abbreviations: ACOS, asthma and COPD overlap syndrome; COPD, chronic obstructive pulmonary disease; ICS, inhaled corticosteroid; LABA, long-acting $\beta_{2}$-agonist; LAMA, long-acting muscarinic antagonist; LTRA, leukotriene receptor antagonist; SABA, short-acting $\beta_{2}$-agonist.
(Table 3; Figure 1). Patients receiving LAMA monotherapy had a milder severity labeling compared with those on dual (ICS/LABA) or triple therapy (ICS/LABA + LAMA). Among patients receiving ICS/LABA + LAMA, a greater proportion had an asthma severity classification of moderate persistent and severe persistent as compared with the LAMA-only and ICS/LABA groups. A similar pattern was observed for physician-perceived exacerbation risk, and this was reflected by patients on triple therapy having the highest mean number of exacerbations over the previous 12 months.

\section{Treatment trends for ACOS patients according to prior diagnosis}

Among the 523 patients with ACOS, 251 (48\%) had preexisting asthma, that is, an initial diagnosis of asthma with a later diagnosis of COPD, 90 (17\%) had pre-existing COPD, and 74 (14\%) were diagnosed with asthma and COPD simultaneously. Prior diagnosis was not known for 105 patients (20\%) for whom the physician confirmed a diagnosis of ACOS but no time from diagnosis was provided, with the result that it was not possible to identify which conditions, if any, were preexisting; treatment data were missing for a further three patients (1\%). Treatment practices were largely similar for patients regardless of their initial diagnosis prior to ACOS (Table 4).

\section{Characterization of ACOS patients and comparison with COPD-only and asthma-only patients}

Patients with ACOS had more symptoms and exacerbations overall than those with either COPD-only or asthma-only (Tables 1 and 5). The most common physician-reported trigger for a worsening of respiratory symptoms was bacterial infection, which was reported for $70.6 \%$ of patients with COPD-only and $70.9 \%$ of patients with ACOS. Physicians reported a higher proportion of patients with ACOS had symptoms equally during the day and night as compared with asthma- or COPD-only patients. A similar pattern was reported by patients, with $40 \%$ of patients with ACOS, $32 \%$ of those with COPD, and $26 \%$ of those with asthma having symptoms with equal frequency during the day and night $(P<0.001$, compared with having symptoms during the daytime only or predominantly during the daytime).

\section{Discussion}

Few randomized clinical trials have been conducted specifically in patients with ACOS and, as a result, this population is not well characterized. The present study is, to the best of our knowledge, one of the most comprehensive 
Table 3 Clinical characteristics of patients with ACOS according to treatment prescribed (physician-reported)

\begin{tabular}{|c|c|c|c|c|}
\hline $\begin{array}{l}\text { Clinical characteristic, } \\
\% \text { of patients }\end{array}$ & $\begin{array}{l}\text { LAMA monotherapy } \\
(n=32)\end{array}$ & $\begin{array}{l}\text { ICS/LABA } \\
(n=100)\end{array}$ & $\begin{array}{l}\text { ICS/LABA + LAMA } \\
(n=154)\end{array}$ & $P$-value ${ }^{a}$ \\
\hline COPD disease severity & $(n=32)$ & $(n=98)$ & $(n=|5|)$ & $<0.0001$ \\
\hline Mild & 46.9 & 19.4 & 11.9 & \\
\hline Moderate & 46.9 & 66.3 & 50.3 & \\
\hline Severe & 3.1 & 14.3 & 28.5 & \\
\hline Very severe & 3.1 & 0 & 8.6 & \\
\hline Do not know & 0 & 0 & 0.7 & \\
\hline Asthma disease severity & $(n=29)$ & $(n=98)$ & $(n=137)$ & 0.0863 \\
\hline Intermittent & 31.0 & 26.5 & 20.4 & \\
\hline Mild persistent & 41.4 & 45.9 & 34.3 & \\
\hline Moderate persistent & 27.6 & 24.5 & 37.2 & \\
\hline Severe persistent & 0 & 3.1 & 8.0 & \\
\hline Symptomatic & 79.0 & 59.7 & 72.6 & \\
\hline Symptoms in last 4 weeks & $(n=32)$ & $(n=100)$ & $(n=154)$ & \\
\hline SOB during exertion & 68.8 & 55.0 & 81.8 & $<0.0001$ \\
\hline Productive cough & 53.1 & 54.0 & 64.3 & 0.1963 \\
\hline Dry cough & 53.1 & 39.0 & 46.1 & 0.309 \\
\hline Wheezing & 34.38 & 31.0 & 47.4 & 0.0261 \\
\hline A tight feeling in the chest & 43.8 & 32.0 & 40.3 & 0.3151 \\
\hline Pre-bronchodilator $\mathrm{FEV}_{1}, \%$ predicted & $(n=22)$ & $(n=47)$ & $(n=87)$ & 0.491 \\
\hline$<30 \%$ & 0 & 0 & 4.6 & \\
\hline $30 \%$ to $<50 \%$ & 36.4 & 40.4 & 39.1 & \\
\hline $50 \%$ to $<80 \%$ & 63.6 & 59.6 & 56.3 & \\
\hline Post-bronchodilator $\mathrm{FEV}_{1}, \%$ predicted & $(n=16)$ & $(n=44)$ & $(n=7 I)$ & 0.6316 \\
\hline$<30 \%$ & 0 & 0 & 2.8 & \\
\hline $30 \%$ to $<50 \%$ & 31.3 & 43.2 & 42.25 & \\
\hline $50 \%$ to $<80 \%$ & 68.8 & 56.8 & 54.9 & \\
\hline
\end{tabular}

Note: ${ }^{2}$ Difference between all three treatment groups.

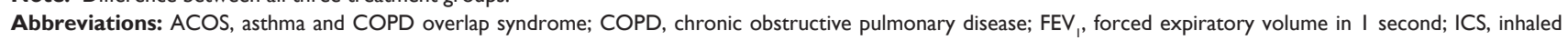
corticosteroid; LABA, long-acting $\beta_{2}$-agonist; LAMA, long-acting muscarinic antagonist; SOB, shortness of breath.
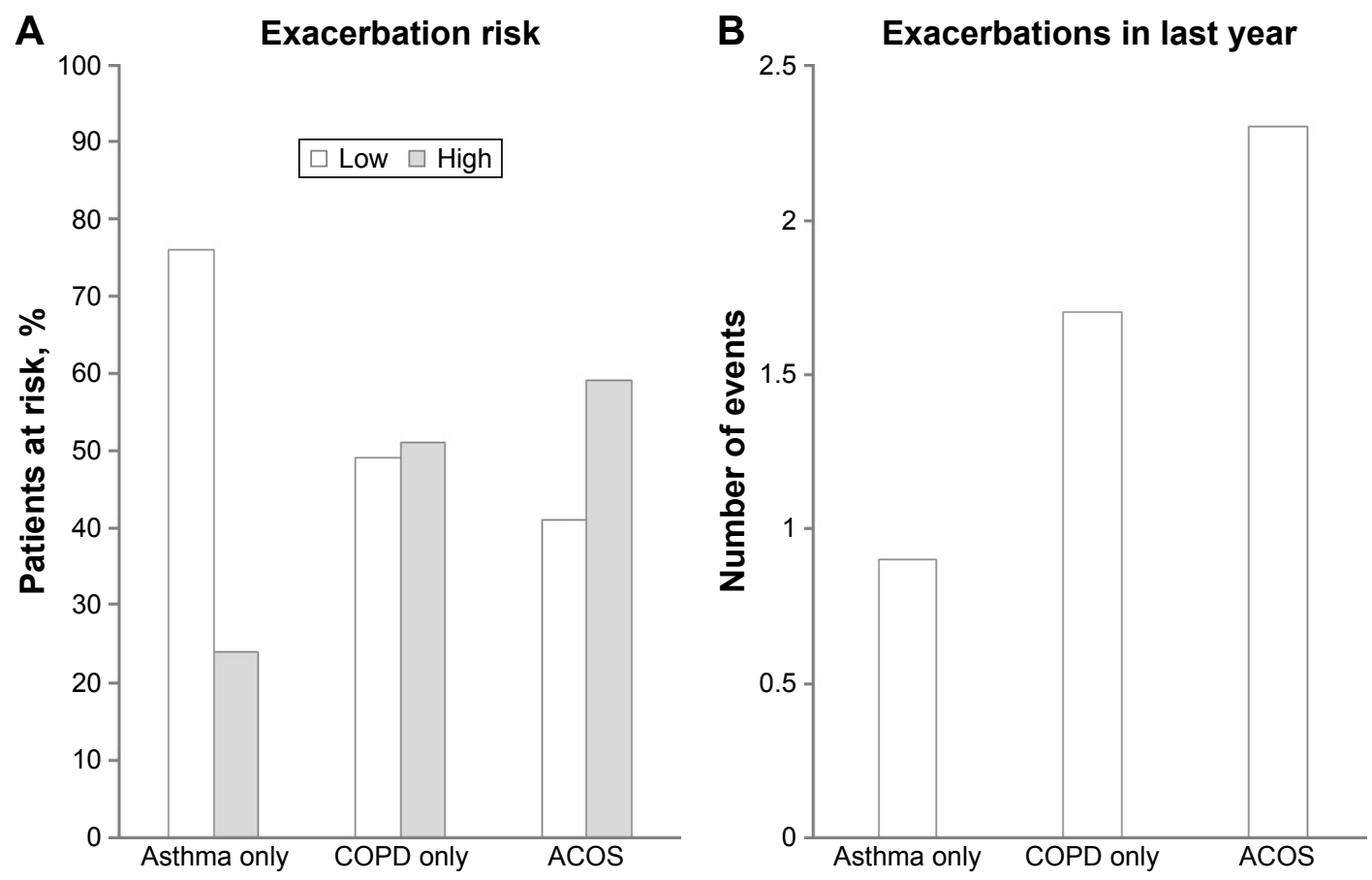

Figure I (A) Physician-reported risk level of exacerbations and (B) mean number of exacerbations ${ }^{\mathrm{a}}$ experienced in the previous 12 months according to disease type. Note: axacerbations defined as physician-confirmed worsening of symptoms beyond day-to-day variation.

Abbreviations: ACOS, asthma and COPD overlap syndrome; COPD, chronic obstructive pulmonary disease. 
Table 4 Comparisons of most commonly prescribed treatment regimens according to pre-ACOS diagnosis

\begin{tabular}{|c|c|c|c|c|}
\hline Treatment & $\begin{array}{l}\text { Pre-existing asthma } \\
(\mathrm{n}=25 \mathrm{I})\end{array}$ & $\begin{array}{l}\text { Pre-existing COPD } \\
(\mathrm{n}=90)\end{array}$ & $\begin{array}{l}\text { Asthma and COPD } \\
\text { diagnosis }^{\mathrm{a}}(\mathrm{n}=74)\end{array}$ & $P$-value \\
\hline LABA alone & 2.4 & 5.6 & 1.4 & 0.2097 \\
\hline ICS alone & 3.2 & 6.7 & 4.1 & 0.3603 \\
\hline LTRA alone & 0 & 3.3 & 1.4 & 0.0197 \\
\hline LAMA alone & 10.0 & I.I & 5.4 & 0.0167 \\
\hline ICS/LABA alone & 17.1 & 18.9 & 24.3 & 0.3795 \\
\hline ICS + LAMA & 4.0 & 0 & 4.05 & 0.1559 \\
\hline ICS/LABA + LAMA & 30.7 & 31.1 & 28.4 & 0.917 \\
\hline ICS/LABA + LTRA & 4.0 & 5.6 & 2.7 & 0.65 \\
\hline Xanthines alone & 0 & 3.3 & 0 & 0.0043 \\
\hline Other & 28.6 & 24.4 & 28.2 & 0.7354 \\
\hline
\end{tabular}

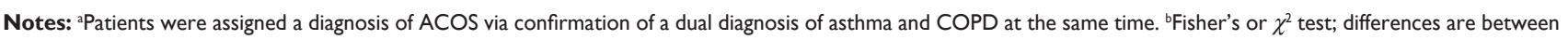
all three treatment groups.

Abbreviations: ACOS, asthma and COPD overlap syndrome; COPD, chronic obstructive pulmonary disease; ICS, inhaled corticosteroid; LABA, long-acting $\beta_{2}$-agonist; LAMA, long-acting muscarinic antagonist; LTRA, leukotriene receptor antagonist.

real-world studies performed to date of patients with ACOS and their treatment regimens.

Patients with ACOS were more likely to be female than those in the COPD group and had higher BMI but were of similar age and smoking status. This similarity between our ACOS and COPD-only groups is in line with the results of other studies, which have demonstrated similar demographic and clinical characteristics in patients with ACOS and COPD ${ }^{14-16}$ and a greater proportion of female patients and fewer current smokers in the ACOS population compared with COPD patients. ${ }^{17,18}$ Compared with our asthma-only patients, patients with ACOS had a higher BMI, and were more likely to be current or exsmokers, which may be due, in part, at least to the inclusion of younger patients in our asthma group - in line with the real-world composition of the two populations. Few other studies have compared asthma-only patients against those with ACOS, but de Marco et al reported a higher prevalence of older patients and lifetime and heavy smokers in patients with ACOS versus those with asthma. ${ }^{19}$ Kitaguchi et al reported a significantly higher proportion of female patients in their group of Japanese patients with asthma, compared with those in COPD and ACOS groups, ${ }^{20}$ and Inui et al reported significantly younger age, lower Brinkman index, and higher $\mathrm{FEV}_{1}$ in patients with asthma versus those with ACOS. ${ }^{21}$ In addition, patients with ACOS were more likely than those with COPD to have a range of comorbidities, including elevated cholesterol levels, hypertension, GERD, diabetes, and arthritis, as previously reported. ${ }^{15,17}$ These comorbidities can impact patients with COPD; for example, GERD may lead to worsening of airway disease as a result of airway inflammation caused by aspiration of gastric acid; $;^{22,23}$ in such cases, inhaled medication is unlikely to treat these symptoms adequately and other strategies will be required. Similarly, obesity ${ }^{24}$ and diabete ${ }^{25}$ can adversely affect patients with respiratory disease and require separate

Table 5 Symptoms experienced in the last 4 weeks (physician-reported)

\begin{tabular}{|c|c|c|c|c|}
\hline Symptom, \% of patients & $\begin{array}{l}\text { Adult asthma-only } \\
(n=9,042)\end{array}$ & $\begin{array}{l}\text { COPD-only } \\
(n=7, I \mid 9)\end{array}$ & $\begin{array}{l}\text { ACOS } \\
(n=523)\end{array}$ & $P$-value ${ }^{a}$ \\
\hline Wheezing & 30.4 & 29.7 & 42.0 & $<0.001$ \\
\hline A tight feeling in the chest & 24.2 & 26.5 & 36.0 & $<0.001$ \\
\hline Short of breath when exposed to trigger & 25.9 & 16.4 & 30.5 & $<0.001$ \\
\hline Bronchospasm/sudden chest tightening & 19.0 & 16.8 & 26.8 & $<0.001$ \\
\hline Regular clearing of throat & 13.0 & 18.6 & 30.3 & $<0.001$ \\
\hline Coughing up blood & 0 & 3.0 & 7.3 & $<0.001$ \\
\hline \multicolumn{5}{|l|}{ Time of day of symptoms } \\
\hline Daytime; primarily daytime & 63.3 & 66.3 & 54.8 & \\
\hline Equally both day and night & 24.1 & 29.6 & 37.6 & $<0.001$ \\
\hline Nighttime; primarily nighttime & 12.6 & 4.1 & 7.6 & \\
\hline Physician perception of symptoms ${ }^{b}$ & $(n=4,602)$ & $(n=3,650)$ & $(n=27 I)$ & \\
\hline Symptomatic (vs not symptomatic) & 50.6 & 70.6 & 73.8 & $<0.001$ \\
\hline
\end{tabular}

Notes: a Difference between all three treatment groups; $\chi^{2}$ test. 'bata collected in 2013 Disease Specific Programme only. Abbreviations: ACOS, asthma and COPD overlap syndrome; COPD, chronic obstructive pulmonary disease. 
consideration. Treatments for these comorbidities may help improve lung function in patients with ACOS, such as improvements in asthma symptom scores and rescue medication use seen in patients with asthma and GERD following treatment with omeprazole alone ${ }^{26}$ and in combination with domperidone, ${ }^{27}$ similar improvements were seen in patients treated with lansoprazole. ${ }^{28}$ A systematic review concluded, however, that treatment for reflux esophagitis in adults with asthma did not improve asthma control. ${ }^{29}$ A clearer characterization of the ACOS patient is needed to understand the effect of age, BMI, GERD, and other comorbidities on respiratory status in order to better understand the optimal treatment for these patients.

Patients with ACOS were most commonly treated with ICS/LABA + LAMA, ICS/LABA, or LAMA monotherapy; only the use of LAMA monotherapy differed significantly between the ACOS and COPD-only groups, with significantly lower use of this treatment option in patients with asthma, as expected. In contrast, there was a significant difference between the ACOS and asthma groups in the proportion of patients receiving each of these treatments, suggesting ACOS treatment is more consistent with COPDonly treatment. These findings could be considered to be in conflict with the current consensus, which recognizes "asthma therapy" (specifically ICS-containing products) as the most appropriate treatment for patients with ACOS. ${ }^{30}$ Indeed, $18.2 \%$ of our patients with ACOS did not receive ICS-containing therapy, suggesting suboptimal treatment of patients who might benefit from ICS treatment.

Examination of the clinical characteristics of patients with ACOS according to the most common treatment for ACOS revealed that more aggressive therapy was associated with more severe COPD, greater physician-perceived risk of exacerbations, more symptoms experienced in the previous 4 weeks, and more exacerbations in the previous year. We observed that primary care physician-only treatment of patients with ACOS was common, accounting for approximately $42 \%$ of ACOS patients. Given the complex nature of the ACOS condition, and the greater level of expertise required to optimally treat such patients, it may be a surprising finding that such a high proportion are not receiving specialist-led care. A more holistic approach to treating patients, including consideration of comorbidities that impact on lung function such as GERD and obesity, is likely needed for the patient with ACOS.

We observed no differences in treatment patterns related to a pre-existing asthma diagnosis, suggesting the disease - or at least the diagnostic pathway to ACOS - does not result in significantly different treatment decisions. The development and adoption of ACOS treatment guidelines ${ }^{3}$ is likely to help in the identification of affected patients and management of their symptoms.

Some limitations of this analysis should be considered. The ACOS patient population was defined as patients with COPD who had comorbid asthma. Not all patients with ACOS receive a formal diagnosis of COPD and asthma; neither is the combination of COPD and characteristics commonly associated with asthma always recognized as ACOS by physicians. Indeed, the current fixed ratio of $\mathrm{FEV}_{1} / \mathrm{FVC}$ used to define obstructive lung disease can lead to false-positive characterizations of obstructive disease in patients with asthma, resulting in incorrect diagnosis of ACOS. However, the derivation of our population was similar to that used by others, ${ }^{14,15,18}$ and our data were similar to the findings of those studies. Our definition of ACOS may be restrictive in terms of the true ACOS population, despite using a recognized primary definition or pre-existing asthma diagnosis. As a result of a longstanding focus on COPD patients with an asthma component, rather than on asthma with a COPD component, the asthma part of the DSP survey excluded asthma patients with comorbid COPD, should these patients exist. This potential phenotype is, therefore, excluded from the ACOS patient sample and may limit the generalizability of the findings to the general ACOS population. In clinical practice, a diagnosis of ACOS is not only based on a confirmed COPD and asthma diagnosis, but through other markers including family history of asthma, atopy, and allergies. Our ACOS sample is, therefore, representative of a subtype of $\mathrm{ACOS}$, which may limit the generalizability of our findings. A more comprehensive sample could be generated if additional measures were taken to identify a broader ACOS patient sample. The number of patients in some of the groups was small, limiting the strength of the conclusions that can be drawn. Finally, differences in the clinical and demographic characteristics of the patient populations, such as younger age in the asthma population and greater level of comorbidities in ACOS patients, may also limit the interpretation of the findings.

Despite these limitations, our ACOS population was well defined and of reasonable size; our findings are, therefore, valid and valuable if the limitations and generalizability outlined earlier are taken into consideration. The quality and quantity of information on ACOS patient cohorts published to date are somewhat limited and the present study, therefore, provides additional insight that complements, supports, and expands on previous findings in this population. 
The present analysis has shown that patients with ACOS have a more severe symptom profile and experience more frequent exacerbations than those with asthma or COPDonly. Furthermore, patients with ACOS experienced more sputum, chest tightness, wheezing and night-time and daytime symptoms than those with COPD-only or asthma-only, although other comorbidities may have been responsible for these symptoms. The majority of patients with ACOS were currently receiving treatment more closely aligned with a COPD-only diagnosis, although the greater use of triple therapy in patients with ACOS versus those with asthmaonly is to be expected, given the opposing disease severity profiles of ACOS and asthma and the lack of approved triple therapies for asthma at the time of the survey. A considerable proportion of patients with ACOS in the present study did not receive any form of ICS therapy and are potentially suboptimally treated according to GINA/GOLD guidelines, ${ }^{3}$ increasing the risk of symptoms and exacerbations. Furthermore, an important unmet need was identified, as a proportion of patients with ACOS experienced exacerbations and symptoms despite receiving triple therapy. No causal relationship between treatment administered and extent of symptoms was explored in this study, but further investigation of potential relationships is needed. In this subgroup of patients, the use of new products and/or novel combinations of products may be warranted.

In conclusion, the present study has shown that most patients with ACOS, as defined in this research, receive similar treatment to patients with COPD. The level of symptoms and exacerbations experienced by these patients suggest a need for more effective treatment. Identification of and knowledge regarding ACOS has improved in recent times, and definitions and treatment guidelines are now available to assist in the management of affected patients. Further research, including well-designed clinical trials in well-defined patient groups, is needed to improve outcomes in this prognostically poor patient population. Patients with comorbidities are frequently excluded from clinical trials; more studies in real-world patients, taking into account their comorbidity profiles, are needed to truly understand this patient population.

\section{Acknowledgments}

This study was supported by AstraZeneca. Medical writing support was provided by Deirdre Carman of Alispera Communications Ltd, funded by AstraZeneca. The authors wish to thank Nicola Johns, a former employee of Adelphi Real World, who provided analytical support and prepared the study report.

\section{Disclosure}

$\mathrm{BD}$ is an employee of AstraZeneca. MS is an employee of Adelphi Real World. The authors report no other conflicts of interest in this work.

\section{References}

1. Global Initiative for Asthma. Pocket guide for asthma management and prevention. 2016 update. Available from: http://ginasthma.org/ wp-content/uploads/2016/04/wms-GINA-2016-main-report-final.pdf. Accessed December 6, 2016.

2. Global Initiative for Chronic Obstructive Lung Disease. Global strategy for the diagnosis, management, and prevention of chronic obstructive pulmonary disease. 2017 report. Available from: http://goldcopd.org/ gold-2017-global-strategy-diagnosis-management-prevention-copd/. Accessed December 6, 2016.

3. Global Initiative for Asthma. Global Initiative for Chronic Obstructive Lung Disease. Diagnosis of diseases of chronic airflow limitation: asthma, COPD and asthma-COPD overlap syndrome (ACOS). Available from: http://ginasthma.org/asthma-copd-and-asthma-copdoverlap-syndrome-acos/. Accessed December 13, 2016.

4. Ding B, Enstone A. Asthma and chronic obstructive pulmonary disease overlap syndrome(ACOS): structured literature review and physician insights. Expert Rev Respir Med. 2016;10(3):363-371.

5. Nielsen M, Bårnes CB, Ulrik CS. Clinical characteristics of the asthmaCOPD overlap syndrome-a systematic review. Int J Chron Obstruct Pulmon Dis. 2015;10:1443-1454.

6. Alshabanat A, Zafari Z, Albanyan O, Dairi M, FitzGerald JM. Asthma and COPD overlap syndrome (ACOS): A systematic review and meta analysis. PLoS One. 2015;10(9):e0136065.

7. Rhee CK, Yoon HK, Yoo KH, et al. Medical utilization and cost in patients with overlap syndrome of chronic obstructive pulmonary disease and asthma. COPD. 2014;11(2):163-170.

8. Ding B, DiBonaventura M, Karlsson N, Ling X. Asthma-chronic obstructive pulmonary disease overlap syndrome in the urban Chinese population: prevalence and disease burden using the 2010, 2012, and 2013 China National Health and Wellness surveys. Int J COPD. 2016; 11:1139-1150.

9. Anderson P, Benford M, Harris N, Karavali M, Piercy J. Real-world physician and patient behaviour across countries: Disease-Specific Programmes - a means to understand. Curr Med Res Opin. 2008;24(11): 3063-3072.

10. Vollmer WM, Gíslason T, Burney P, et al. Comparison of spirometry criteria for the diagnosis of COPD: results from the BOLD study. Eur Respir J. 2009;34(3):588-597.

11. ICC/ESOMAR. ICC/ESOMAR Contents International Code on Market, Opinion and Social Research and Data Analytics. 2016. Available from: https://www.esomar.org/uploads/public/knowledge-and-standards/ codes-and-guidelines/ICCESOMAR_Code_English_.pdf. Accessed April 14, 2017.

12. US Department of Health and Human Services. Summary of the HIPAA Privacy Rule May 2003. Available from: http://www.hhs.gov/sites/ default/files/privacysummary.pdf. Accessed April 14, 2017.

13. EphMRA. Code of Conduct. Updated January 2016. Available from: http://www.ephmra.org/Code-of-Conduct-Support. Accessed April 14, 2017.

14. Cosio BG, Soriano JB, López-Campos JL, et al; CHAIN Study. Defining the Asthma-COPD overlap syndrome in a COPD cohort. Chest. 2016;149(1):45-52.

15. Chung WS, Lin CL, Kao CH. Comparison of acute respiratory events between asthma-COPD overlap syndrome and COPD patients: a population-based cohort study. Medicine (Baltimore). 2015; 94(17):e755.

16. Suzuki T, Tada Y, Kawata N, et al. Clinical, physiological, and radiological features of asthma-chronic obstructive pulmonary disease overlap syndrome. Int J Chron Obstruct Pulmon Dis. 2015;10:947-954. 
17. van Boven JF, Román-Rodríguez M, Palmer JF, Toledo-Pons N, Cosío BG, Soriano JB. Comorbidome, pattern and impact of asthmaCOPD overlap syndrome (ACOS) in real-life. Chest. 2016;149(4): 1011-1020.

18. Kim MA, Noh CS, Chang YJ, et al. Asthma and COPD overlap syndrome is associated with increased risk of hospitalisation. Int J Tuberc Lung Dis. 2015;19(7):864-869.

19. de Marco R, Marcon A, Rossi A, et al. Asthma, COPD and overlap syndrome: a longitudinal study in young European adults. Eur Respir J. 2015;46(3):671-679.

20. Kitaguchi Y, Yasuo M, Hanaoka M. Comparison of pulmonary function in patients with COPD, asthma-COPD overlap syndrome, and asthma with airflow limitation. Int J Chron Obstruct Pulmon Dis. 2016;11: 991-997.

21. Inui T, Nakamoto K, Sada M, et al. Phenotypic characterization of asthma-COPD overlap syndrome: comparison with asthma and COPD. Eur Respir J. 2015;46(Suppl 59):PA2357.

22. Benson VS, Müllerová H, Vestbo J, Wedzicha JA, Patel A, Hurst JR; Evaluation of COPD Longitudinally to Identify Predictive Surrogate Endpoints (ECLIPSE) Investigators. Associations between gastrooesophageal reflux, its management and exacerbations of chronic obstructive pulmonary disease. Respir Med. 2015;109(9):1147-1154.

23. Ingebrigtsen TS, Marott JL, Vestbo J, Nordestgaard BG, Hallas J, Lange P. Gastro-esophageal reflux disease and exacerbations in chronic obstructive pulmonary disease. Respirology. 2015;20(1):101-107.
24. Hanson C, Rutten EP, Wouters EF, Rennard S. Influence of diet and obesity on COPD evelopment and outcomes. Int J Chron Obstruct Pulmon Dis. 2014;9:723-733.

25. Mannino DM, Thorn D, Swensen A, Holguin F. Prevalence and outcomes of diabetes, hypertension and cardiovascular disease in COPD. Eur Respir J. 2008;32(4):962-969.

26. Sandur V, Murugesh M, Banait V, et al. Prevalence of gastro-esophageal reflux disease in patients with difficult to control asthma and effect of proton pump inhibitor therapy on asthma symptoms, reflux symptoms, pulmonary function and requirement for asthma medications. J Postgrad Med. 2014;60(3):282-286.

27. Sharma B, Sharma M, Daga MK, Sachdev GK, Bondi E. Effect of omeprazole and domperidone on adult asthmatics with gastroesophageal reflux. World J Gastroenterol. 2007;13(11):1706-1710.

28. Littner MR, Leung FW, Ballard ED 2nd, Huang B, Samra NK; Lansoprazole Asthma Study Group. Effects of 24 weeks of lansoprazole therapy on asthma symptoms, exacerbations, quality of life, and pulmonary function in adult asthmatic patients with acid reflux symptoms. Chest. 2005;128(3):1128-1135.

29. Coughlan JL, Gibson PG, Henry RL. Medical treatment for reflux oesophagitis does not consistently improve asthma control: a systematic review. Thorax. 2001;56(3):198-204.

30. Soler-Cataluña JJ, Cosío B, Izquierdo JL, et al. Consensus document on the overlap phenotype COPD-asthma in COPD. Arch Bronconeumol. 2012;48(9):331-337. 


\section{Supplementary material}

Table SI Patient baseline characteristics according to region

\begin{tabular}{|c|c|c|c|c|c|c|}
\hline & \multicolumn{3}{|l|}{ USA } & \multicolumn{3}{|l|}{ EU5 } \\
\hline & $\begin{array}{l}\text { Asthma } \\
(n=2,157)\end{array}$ & $\begin{array}{l}\text { COPD } \\
(n=1,632)\end{array}$ & $\begin{array}{l}\text { ACOS } \\
(n=169)\end{array}$ & $\begin{array}{l}\text { Asthma } \\
(\mathrm{n}=6,885)\end{array}$ & $\begin{array}{l}\text { COPD } \\
(n=5,487)\end{array}$ & $\begin{array}{l}\text { ACOS } \\
(n=354)\end{array}$ \\
\hline \multicolumn{7}{|l|}{ Demographics } \\
\hline Age, years & 42.5 & 67.4 & 64.5 & 41.8 & 65.5 & 65.5 \\
\hline Male, \% & 40.1 & 55.2 & 48.5 & 46.0 & 69.2 & 54.7 \\
\hline $\mathrm{BMI}, \mathrm{kg} / \mathrm{m}^{2}$ & 28.6 & 27.8 & 29.5 & 25.2 & 26.3 & 26.6 \\
\hline Never smoker, \% & 79.2 & 2.0 & 4.2 & 67.3 & 2.9 & 6.1 \\
\hline \multicolumn{7}{|l|}{ Comorbidities, \% } \\
\hline Elevated cholesterol & 16.9 & 39.5 & 41.6 & 8.5 & 25.5 & 23.4 \\
\hline Hypertension & 26.1 & 67.4 & 61.5 & 17.9 & 56.2 & 53.8 \\
\hline Arthritis & 9.0 & 26.4 & 28.6 & 3.1 & 8.4 & 10.8 \\
\hline Diabetes & 7.7 & 17.7 & 28.0 & 5.5 & 17.8 & 19.0 \\
\hline GERD & 18.0 & 22.8 & 23.6 & 8.2 & 10.5 & 16.9 \\
\hline \multicolumn{7}{|l|}{ Treatment, \% } \\
\hline LABA alone & 0.1 & 1.5 & 2.4 & 1.5 & 6.6 & 3.4 \\
\hline ICS alone & 14.8 & 3.5 & 7.7 & 15.7 & 2.6 & 2.3 \\
\hline LAMA alone & 0.5 & 20.5 & 8.3 & 0.3 & 19.0 & 7.4 \\
\hline ICS/LABA alone & 34.1 & 24.2 & 23.8 & 43.8 & 14.5 & 20.7 \\
\hline ICS/LABA + LAMA & 0.7 & 31.6 & 20.2 & 1.7 & 32.1 & 36.9 \\
\hline \multicolumn{7}{|l|}{ Symptoms, \% } \\
\hline SOB & 16.7 & 28.5 & 31.4 & 15.0 & 27.9 & 31.2 \\
\hline SOB during exertion & 45.6 & 66.6 & 66.9 & 44.7 & 73.0 & 77.3 \\
\hline Wheezing & 39.0 & 34.5 & 49.1 & 27.7 & 28.3 & 38.5 \\
\hline Exacerbations $^{\mathrm{a}}$ in last 12 months, $\mathrm{n}$ & 0.9 & 1.5 & 2.1 & 0.9 & 1.8 & 2.4 \\
\hline
\end{tabular}

Note: aExacerbations defined as physician-confirmed worsening of symptoms beyond day-to-day variation.

Abbreviations: ACOS, asthma and COPD overlap syndrome; COPD, chronic obstructive pulmonary disease; EU5, Spain, Italy, France, Germany, and the UK; GERD, gastroesophageal reflux disease; ICS, inhaled corticosteroid; LABA, long-acting $\beta_{2}$-agonist; LAMA, long-acting muscarinic antagonist; SOB, shortness of breath.

\section{Publish your work in this journal}

The International Journal of COPD is an international, peer-reviewed journal of therapeutics and pharmacology focusing on concise rapid reporting of clinical studies and reviews in COPD. Special focus is given to the pathophysiological processes underlying the disease, intervention programs, patient focused education, and self management protocols.

\section{Dovepress}

This journal is indexed on PubMed Central, MedLine and CAS. The manuscript management system is completely online and includes a very quick and fair peer-review system, which is all easy to use. Visit http://www.dovepress.com/testimonials.php to read real quotes from published authors. 